\title{
Formação de professores e as relações étnico-raciais em escola bilíngue: possibilidades e limites
}

\author{
Teacher training and ethnic-racial relations in a bilingual school: possibilities and limits \\ Formación docente y relaciones étnico-raciales en una escuela bilingüe: posibilidades y límites
}

Recebido: 27/01/2022 | Revisado: 31/01/2022 | Aceito: 04/02/2022 | Publicado: 06/02/2022

\author{
Marceli Lucia Paveglio Romeu \\ ORCID: https://orcid.org/0000-0002-7356-8241 \\ Universidade Federal do Pampa, Brasil \\ E-mail: mardan.luna@gmail.com \\ Simone Silva Alves \\ ORCID: https://orcid.org/0000-0002-1292-4038 \\ Universidade Federal do Pampa, Brasil \\ E-mail: simonealves@unipampa.edu.br \\ Vitor Garcia Stoll \\ ORCID: https://orcid.org/0000-0002-4133-9313 \\ Universidade Federal de Pelotas, Brasil \\ E-mail: vitorgarciastoll@gmail.com \\ Leticia Leite Chaves \\ ORCID: https://orcid.org/0000-0003-3247-8685 \\ Universidade Federal do Pampa, Brasi \\ E-mail: lechavess95@gmail.com
}

\begin{abstract}
Resumo
Este estudo apresenta um recorte dos estudos desenvolvidos num Mestrado Profissional em Educação, vinculado a uma universidade situada no extremo sul do Brasil. Objetivou-se identificar a percepção de educadores de uma escola bilíngue sobre a educação para as relações étnico-raciais e verificar que temas/metodologias consideram fundamentais para trabalhar com Libras e relações étnico-raciais na escola. Metodologicamente classifica-se quanto a natureza como qualitativa e procedimentalmente é um estudo de caso, no qual, utilizou-se um questionário semiestruturado como instrumento para coleta de dados. Resultados indicam que apesar de conhecerem a legislação e saberem que existe obrigatoriedade, a maioria não possuía formação inicial ou continuada para desenvolver a temática em sala de aula. Aponta-se ainda, que as brincadeiras e jogos educativos foram os principais temas destacados como fundamentais para abordagem da Libras e relações étnico-raciais. Por fim, destacamos como fundamental incentivar pesquisas e produção de materiais didático pedagógicos sobre a educação para relações étnico-raciais em escolas bilíngues.
\end{abstract}

Palavras-chave: Educação para as relações étnico-raciais; Ensino; Formação de professores; Libras.

\begin{abstract}
This study presents an excerpt of the studies developed in a Professional Master's Degree in Education, linked to a university located in the extreme south of Brazil. The objective was to identify the perception of educators from a bilingual school about education for ethnic-racial relations and to verify which themes/methodologies they consider fundamental to work with Libras and ethnic-racial relations at school. Methodologically, it is classified as qualitative in nature and procedurally it is a case study, in which a semi-structured questionnaire was used as an instrument for data collection. Results indicate that despite knowing the legislation and knowing that it is mandatory, most did not have initial or continuing training to develop the theme in the classroom. It is also pointed out that educational games and games were the main themes highlighted as fundamental for approaching Libras and ethnic-racial relations. Finally, we emphasize how fundamental it is to encourage research and the production of pedagogical materials on education for ethnic-racial relations in bilingual schools.
\end{abstract}

Keywords: Education for ethnic-racial relations; Teaching; Teacher training; Pounds.

\section{Resumen}

Este estudio presenta un extracto de los estudios desarrollados en una Maestría Profesional en Educación, vinculada a una universidad ubicada en el extremo sur de Brasil. El objetivo fue identificar la percepción de educadores de una escuela bilingüe sobre la educación para las relaciones étnico-raciales y verificar qué temas/metodologías consideran fundamentales para trabajar con Libras y las relaciones étnico-raciales en la escuela. Metodológicamente se clasifica como de carácter cualitativo y procedimentalmente es un estudio de caso, en el cual se utilizó como instrumento de recolección de datos un cuestionario semiestructurado. Los resultados indican que a pesar de conocer la legislación y 
saber que es obligatoria, la mayoría no tuvo formación inicial ni continua para desarrollar el tema en el aula. También se señala que los juegos y juegos educativos fueron los principales temas destacados como fundamentales para el abordaje de Libras y las relaciones étnico-raciales. Finalmente, destacamos cuán fundamental es incentivar la investigación y la producción de materiales didácticos sobre la educación para las relaciones étnico-raciales en las escuelas bilingües.

Palabras clave: Educación para las relaciones étnico-raciales; Enseñanza; Formación de profesores; Libras.

\section{Introdução}

A Língua Brasileira de Sinais (Libras) é "reconhecida como meio legal de comunicação e expressão" (Brasil, 2002) das comunidades surdas brasileiras e apresenta todos os aspectos gramaticais, assim como a língua portuguesa. Como diferença, posta-se que a Libras se processa de forma visual espacial, enquanto as línguas orais se processam de forma oralauditiva.

O processo de reconhecimento da Língua de Sinais foi lento no Brasil. As lutas da comunidade surda por reconhecimento e valorização da Libras, bem como por cursos de formação para a atuação de surdos e ouvintes foram responsáveis pela mudança de status, chegando à Lei n. 10.436 de 2002. "Essa lei garante à pessoa surda o direito de usar livremente a sua língua, disseminada com o aval e o apoio do Estado" e dá outras providências (Marques et al., 2020, p. 6). De maneira análoga, a busca pela justiça social em questões étnico-raciais também tem apoio legal. As Leis n. 11.645 de 2008, n. 9.394 de 1996 e n. 10.639 de 2003 são as responsáveis por estabelecer, nas Diretrizes e Bases da Educação Nacional, a obrigatoriedade da temática "História e Cultura Afro-Brasileira e Indígena" nos estabelecimentos públicos e privados de ensino fundamental e médio.

Partimos da compreensão primordial de que a comunidade surda sofre com o preconceito e também com a perda de seu direito de cidadania. As políticas públicas, mesmo quando voltadas para as minorias, como à população negra, ainda não são capazes de garantir a integração de direitos das pessoas surdas. A comunidade surda, no entanto, segue em luta pelos direitos dentro da sociedade como cidadãos, e também pelos direitos dentro das escolas bilíngues. Na intersecção desses grupos, é necessário apontar-se estratégias de inclusão socio-educacionais que incluam os estudantes surdos negros como parte da luta de ambas as classes.

Neste ínterim, é indispensável que este ensino, dentro das relações étnico-raciais, ocorra, primeiramente, em Libras, no ambiente escolar. O currículo deve ser capaz de permitir ao aluno apropriar-se por completo da língua, pois "[...] lutar contra o racismo, trabalhar para o fim da desigualdade social e racial, empreender uma possível mudança nas relações étnicoraciais também é tarefa da escola" (Alves et al., 2016, p. 16).

O ensino da Libras é fundamental para os surdos e deve permear os momentos de estudo e aprofundamento sobre as relações étnico-raciais em escolas bilíngues. O ensino deve ser promovido por pessoas que sejam fluentes em Libras, com metodologias que sejam apropriadas para ensino da primeira língua e seguir um currículo que permita ao aluno apropriar-se por completo da língua e dos conceitos.

Neste sentido, é importante que a comunidade surda também tenha acesso à temática, para além, ensinada em Libras. A inclusão social precisa ser plena e para os surdos de todas as situações étnico-raciais. Desse modo, torna-se possível derrubar barreiras existentes nas escolas ou em qualquer outro lugar.

A Lei n. 10.639/03 fez emergir a demanda de formação docente capacitada, fazendo os cursos de formação de professores repensarem os currículos e práticas, para a Educação das Relações Étnico-raciais e o Ensino de História e Culturas Afro-brasileiras e Africanas. Assim, tornaram-se conteúdos obrigatórios nos cursos de licenciatura, inclusive para os alunos surdos na escola bilíngue. Eles têm o direito de inclusão, o qual deve ser objeto de avaliação dos cursos por parte do Ministério da Educação e Cultura. 
É necessária a presença de profissionais bilíngues nas escolas de surdos, sejam públicas ou privadas, porque não tem como haver inclusão desses alunos sem professores capacitados para exercer essa atividade, sem conhecimento de Libras e da cultura surda. Os professores precisam estar preparados para receber todos os tipos de alunos, sejam eles surdos ou com qualquer outra diferença. Todo o estudante tem o direito de aprender e receber um ensino de qualidade de acordo com suas necessidades, através de pessoas aptas e qualificadas para ensiná-los. Sendo assim, os alunos surdos têm direito de aprender na primeira língua deles que é a Libras e na segunda língua que é a portuguesa.

Salienta-se que na literatura a educação inclusiva tem sido construída com base em lutas contra os preconceitos com a cultura surda e alunos surdos, pois todos precisam de igualdade nos seus direitos à educação inclusiva e educação bilíngue na escola. Percebemos que há um aumento de conhecimento na área da educação de surdos e da Libras pelos licenciandos. A regulamentação da Lei n. 10.436/2002, através do Decreto-Lei n. 5.626/2005, proporcionou estudos e procedimentos sobre o ensino da Língua Brasileira de Sinais, no contexto educacional do nosso país com a formação de professores e também intérpretes de Língua de Sinais, visto que Libras é ofertada como disciplina obrigatória nos cursos de formação de professores.

É importante identificar cursos que possibilitem a fluência em Libras pelos diversos profissionais, pois será a formação de professores e bacharéis que tenham domínio das línguas de estudo, bem como as culturas para garantir o compromisso e a responsabilidade que é assumida ao ensinar outra língua ou traduzir e interpretar para exercer atividades de professor, pesquisador, tradutor e intérprete, revisor de texto, dentre outros.

O Decreto n. 5.626/05 traz em seu terceiro capítulo, no artigo $4^{\circ}$, que apresenta duas exigências distintas em relação ao docente de Libras que deverá atuar na Educação Superior: "A formação de docentes para o ensino de Libras nas séries finais do ensino fundamental, no ensino médio e na educação superior deve ser realizada em nível superior, em curso de graduação de licenciatura plena em Letras: Libras ou em Letras: Libras/Língua Portuguesa como segunda língua" (Brasil, 2005). Esses professores podem ser surdos ou ouvintes, desde que sejam fluentes na Libras e conheçam as especificidades culturais e linguísticas da comunidade surda.

O mesmo Decreto dispõe sobre a formação do professor bilíngue e o instrutor surdo de Libras, também a formação do tradutor e intérprete de Libras/língua portuguesa e o direito dos surdos ao acesso de informações em Libras. Por outro lado, o ensino da Libras não pode se limitar apenas aos cursos de formação de docentes, mas para profissionais de todas as áreas, como área da saúde, segurança, comercial, empresarial, social, cultural, econômica e entre outras mais. Assim, é possível ampliar a acessibilidade da comunidade surda em todos os espaços da sociedade. Neste sentido,

[...] a formação de professores deveria garantir uma sólida cultura que lhes permita atingir uma aguda consciência da realidade em que vão atuar associadas a um consistente preparo teórico-científico que os capacite à realização de uma prática pedagógica coerente. [...] Condições adequadas de trabalho que lhes permitam atualização constante, preparação consistente de suas atividades curriculares e atendimento às necessidades pedagógicas dos alunos, revendo e reelaborando os conteúdos e os métodos do ensino ministrado (Saviani, 2010, p. 53).

Conforme mencionado, na educação bilíngue como política educacional para surdos, a Língua de sinais é apresentada como primeira língua e a Língua Portuguesa, a segunda. As pessoas surdas têm direito à educação adequada às suas necessidades, ou seja, educação bilíngue. O entendimento da Libras como língua materna, ajuda a compreender conceitos que irão nortear o pensamento, visão de mundo e servir como língua mediadora para aprendizagem do português como segunda língua e todos os demais componentes curriculares. Por outro lado, o português permitirá aos alunos surdos maior acesso à comunicação, fortalecerá suas estruturas linguísticas e promoverá a integração na cultura da escuta.

De acordo com Skiliar (1998, p. 1) “[...] a proposta da educação bilíngue para surdos pode ser definida como uma oposição aos discursos e às práticas clínicas hegemônicas características da educação e da escolarização dos surdos nas últimas décadas e como um reconhecimento político da surdez como diferença". 
No entanto, apenas reconhecer o que foi exposto acima, não é suficiente para reduzir o problema educacional das pessoas surdas. É necessário realizar processo educacional baseado em políticas que garantam que os alunos surdos estejam em igualdade com os alunos ouvintes. Os profissionais e pessoas envolvidas na educação especial devem estar sempre atualizados dessas questões para que todos respeitem seus direitos.

Para além disso, os currículos devem adaptar-se às necessidades dos surdos e não vice-versa. "As escolas, portanto, terão de oferecer oportunidades curriculares que correspondam às crianças com capacidades e interesses distintos. As crianças devem receber apoio pedagógico suplementar no currículo regular e não um diferenciado" (Unesco, 1994, p. 22).

Desse modo, a escola deve disponibilizar um profissional fluente na Libras para facilitar o educador no ensino de suas aulas e/ou utilizar recursos didáticos adaptados para pessoas com deficiência. Esse material já é oferecido por órgãos públicos, tornando a sala de aula acessível para todos, de forma que a escola busque soluções criativas para o ensino satisfatório. Para que ocorra a inclusão escolar desses alunos, é necessário investir na formação de professores e compreender que não apenas os surdos devem aprender Libras, mas os ouvintes também precisam. Conforme corroboram França \& Barroso (2021, p. 9), “[...] é interessante, portanto, destacar a necessidade do aprendizado da Libras por pessoas ouvintes, que aconteça a capacitação de professores, a abertura de mais espaço para intérpretes e a efetivação da educação bilíngue, estas serão formas admiráveis de propiciar uma educação inclusiva".

A lei n. 10.436 de 24 de abril de 2002, defende a obrigatoriedade do curso de Libras nas diretrizes curriculares dos cursos de formação e educação especial, para atender as necessidades da comunidade surda. Para que ocorra o ensino qualificado aos alunos surdos faz-se necessário que haja mais investimentos na área da educação, dessa forma é primordial que tenham cursos de formação para professores bilíngues, que prepare os mesmos para ministrar aulas em língua de sinais, pois somente por meio da sua língua, os alunos conseguirão entender os conteúdos ministrados.

Defendemos então que é de extrema importância continuar lutando para defender os direitos dos alunos surdos, para que as leis sejam respeitadas, possibilitando a formação de, cada vez mais, professores bilíngues, oferecendo aos alunos o acesso a um ensino de qualidade e, para além disso, "[...] reconhecimento a sua especificidade, não aceitando a inclusão pela deficiência, mas pela equidade de diferença linguística" (Vale et al., 2021, p. 2).

Aclarados tais conceitos, esse artigo apresenta um recorte dos estudos desenvolvidos num Mestrado Profissional em Educação, vinculado a uma universidade federal situada no extremo sul do Brasil. Buscou-se como objetivos identificar a percepção de educadores de uma escola bilíngue sobre a educação para as relações étnico-raciais e verificar que temas/metodologias consideram fundamentais para trabalhar com Libras e relações étnico-raciais na escola.

Sendo assim, este estudo foi estruturado em quatro seções específicas, sendo a primeira a introdução. A segunda, mostra as escolhas metodológicas, os procedimentos para coleta de dados e a descrição do método de análise. Na terceira etapa, são apresentados os resultados e sua discussão à luz do referencial teórico. E por fim, são tecidas algumas considerações acerca do percurso.

\section{Metodologia}

Metodologicamente, este estudo é classificado como qualitativo porque leva em conta aspectos não quantificáveis da realidade e tem como foco compreender e explicar a dinâmica das relações sociais (Minayo, 2017; Gil, 2017). Trabalha-se "com o universo de significados, motivos, aspirações, crenças, valores e atitudes, o que corresponde a um espaço mais profundo das relações, dos processos e dos fenômenos que não podem ser reduzidos à operacionalização de variáveis" (Minayo, 2017, p. 14). Assim, preocupou-se em pesquisar, qualitativamente, a temática das relações étnico-raciais em uma escola bilíngue. 
No que tange aos procedimentos, classifica-se como estudo de caso (Gil, 2017), pois os sujeitos da pesquisa restringem-se aos professores de uma escola bilíngue situada na cidade de Rio Grande/RS, instituição em que uma das autoras irá realizar um projeto de intervenção de formação continuada. Participaram da pesquisa, dez sujeitos.

O instrumento de coleta de dados foi um questionário diagnóstico organizado no Google Forms, realizado no mês de outubro de 2021. Segundo Gil (2019), um questionário pode ser definido como uma técnica que consiste em elaborar questões escritas com a finalidade de compreender opiniões, crenças, interesses, experiências, dentre outros. A seguir apresenta-se as questões aplicadas:

1) Você conhece a Lei 10.639/2003 que torna obrigatório o ensino de história e cultura africana/afro-brasileira na educação básica?

2) Você fez alguma formação sobre educação para as relações étnico-raciais?

3) Caso a resposta anterior seja SIM, foi um curso de:

( ) Graduação ( ) Especialização ( ) Curso de curta duração

4) Há quanto tempo que você fez a ÚLTIMA formação sobre a educação para as relações étnico-raciais?

5) Caso a resposta da questão 3 (três) seja NÃO, foi:

( ) Falta de tempo

( ) Falta de interesse

( ) Falta de recursos financeiros

( ) A grade curricular não ofertava e/ou curso de formação não abordava essa temática

6) Você trabalha com a temática das relações étnico-raciais com os alunos?

7) Você considera importante um curso que relacione a libras com a diversidade étnica cultural?

8) Você gostaria de participar de um projeto de formação continuada de professores sobre Libras e relações étnicoraciais na escola?

9) Na sua concepção quais temas/metodologias você considera fundamental para um trabalho com Libras e relações étnico-raciais na escola?

\section{Resultados e Discussão}

Na primeira questão, "Você conhece a Lei 10.639/2003 que torna obrigatório o ensino de história e cultura africana/afro-brasileira na educação básica?”, constatamos que todos os professores (100\%) conheciam-na. Esse dado é importante, porque é necessário mostrar que a história oficial da trajetória do Brasil negou aos africanos a condição de sujeitos históricos, pois no meio acadêmico adotou uma ideologia que os negros eram uma raça inferior, motivo pela qual, a verdadeira história da África e dos afro-brasileiros têm sido negadas nas instituições educacionais. Diante disso, os negros, se organizam e lutam pelos direitos à vida digna e cidadã. É necessário contextualizar a lei no espaço escolar e "[...] mais que conhecer a Lei é necessário colocá-la em prática, pois urge que os professores estejam preparados através de cursos de formação continuada para abordarem essa temática com os estudantes da Educação Básica” (Alves et al., 2021).

Quando questionados se já realizaram alguma formação sobre educação para as relações étnico-raciais, 60\% afirmaram que sim. No entanto, $40 \%$ não tiveram nenhuma formação sobre essa temática, o que causa preocupação, pois percebemos que algumas áreas do conhecimento são contempladas ou priorizadas em detrimento a outras, e assim nos questionamos: Quem faz as escolhas dos temas a serem oferecidos para formação continuada desses professores? Os professores podem escolher as temáticas? A temática das relações étnico-raciais não é relevante, mesmo tendo as legislações e diretrizes que tratam da obrigatoriedade nos currículos da educação básica? Nas palavras de Miranda (2012, p. 03) “[...] 
descolonizando as mentes, a escola estará cumprindo sua função social e oportunizando a todos, em iguais condições a posse do conhecimento produzido pela humanidade".

Outro dado relevante é que $90 \%$ dos pesquisados teve contato com a temática em cursos de curta duração, $10 \%$ em especializações e nenhuma menção à graduação. Essas informações revelam que normalmente a formação inicial não contempla a temática da educação para relações étnico-raciais, mesmo tendo obrigatoriedade. Neste sentido, “[...] é de suma importância que os cursos de formação inicial reservem tempo e espaço para a socialização e discussão desses saberes e que estes possam ser problematizados durante o curso. Assim, é importante que professores em processo de formação possam se questionar: como compreendo e aprendi relações étnico-raciais?” (Rodrigues \& Silva, 2021, p. 5).

Ao serem indagados "Há quanto tempo que você fez a última formação sobre a educação para as relações étnicoraciais?", apenas 10\% dos professores realizaram-na há menos de um ano. A maioria (50\%) faz cinco anos ou mais, 20\% há três anos e os outros $20 \%$ há dois anos. Dessa forma podemos inferir que $90 \%$ dos pesquisados não tiveram formação sobre essa temática recentemente. Nesse sentido, faz-se importante, especialmente, nesse contexto histórico atual em que o preconceito e a discriminação às diferentes culturas e etnias se fazem tão presentes. Pois atualmente percebemos aumento da violência contra as pessoas que não fazem parte da cultura europeia tanto no cenário político, econômico e socioeducacional brasileiro. De acordo com Oliveira et al. $(2021$, p. 2) “[...] a situação se torna ainda mais complexa quando se discorre acerca de jovens negros e negras, visto que, hoje estes são os que lideram as estatísticas de pertencimento à famílias pobres e que protagonizam os piores indicadores sociais do país". A exemplo, negros são $147 \%$ mais propensos a serem vítimas de homicídio do que não-negros (Cerqueira \& Coelho, 2017).

Na questão "Você trabalha com a temática das relações étnico-raciais com os alunos?", todos (100\%) responderam que sim. No entanto, nos questionamos de que forma esses professores desenvolvem-na em sala de aula, visto que, 50\% não fizeram uma formação específica nessa área. Como bem explicita Munanga (2005, p.15), “[...] alguns professores, por falta de preparo ou por preconceitos neles inseridos, não sabem lançar mão das situações flagrantes de discriminação no espaço escolar e na sala como momento pedagógico privilegiado de conscientização". Neste sentido, reforça-se que faz-se necessário, cada vez mais, a ampliação das formações continuadas. Para Miranda (2012), é compreensível que a inclusão dos negros na construção da história brasileira, tenha que ter sido por força política, ou seja, por Lei, porque de outra forma, ela não aconteceria. Diante da obrigatoriedade de pôr em prática a Lei sancionada, cabe ao professor trabalhar a questão.

Quando questionados sobre como os professores consideram relevante um curso que relacione a Libras com a diversidade étnica cultural, todos (100\%) responderam que essa temática é importante para formação continuada de professores. Para Pimenta (2013, p. 120), a observância da Lei n. 10.639/2003 e da Lei n. 11645/2008, necessita de investimento na formação de professores, “[...] do mapeamento e divulgação de experiências pedagógicas das escolas, da articulação entre os sistemas de ensino e a confecção de livros e materiais didáticos que abordam a questão étnico-racial da nação brasileira". Defendemos que a formação continuada de professores é fundamental na promoção da inclusão através da diversidade étnico-racial tendo como base os fundamentos da pedagogia bilíngue e da pedagogia antirracista na escola.

Na última questão, "Na sua concepção quais temas/metodologias você considera fundamental para um trabalho com Libras e relações étnico-raciais na escola?", foram citados com maior frequência as brincadeiras populares (100\%), conforme figura 01. Para Costa (2004) as brincadeiras, além de relevantes cultural e socialmente, possuem importante papel do ponto de vista psicológico. "Através do brincar, a criança vê e constrói o mundo, expressa aquilo que tem dificuldade de colocar em palavras. Sua escolha é motivada por processos e desejos íntimos pelos seus problemas e ansiedades e sobretudo pelo desejo de transpor sua condição infantil e ascender a lógica do mundo adulto" (Costa, 2004, p. 20) 
Figura 1. Respostas dos sujeitos ao último questionamento.

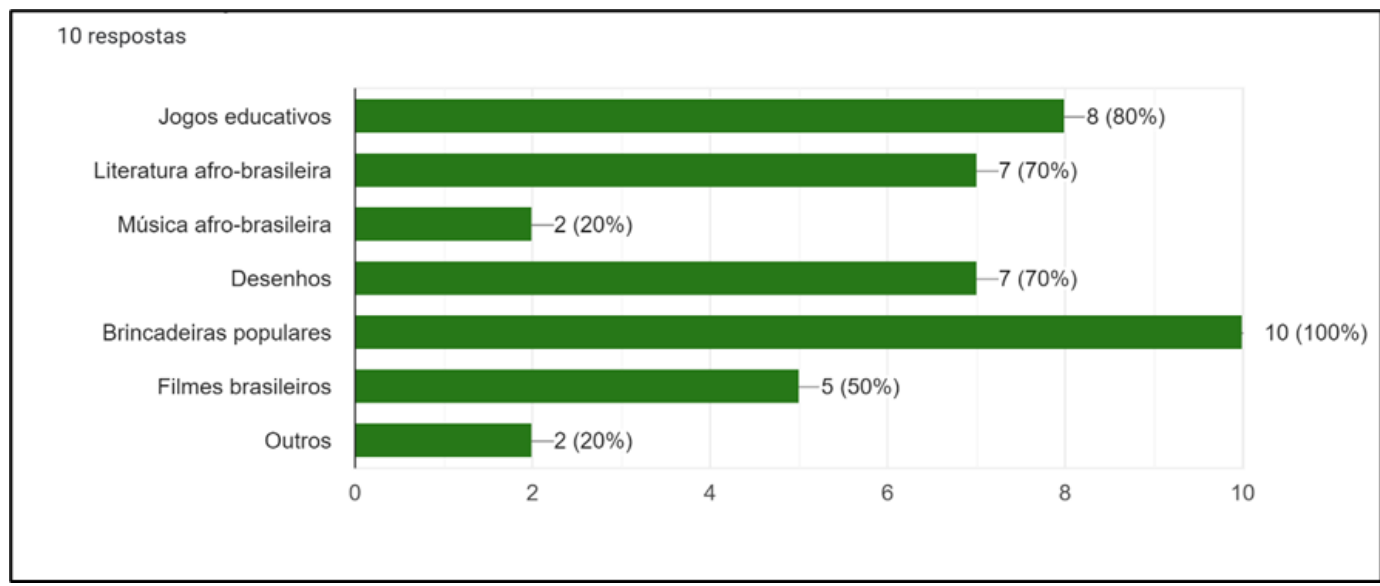

Fonte: Autores.

De acordo com Muller (2013, p. 44), a partir dos jogos - segundo tema mais citado, 80\% - "[...] pode-se construir na sala de aula um espaço propício ao aprendizado que, apesar de diversificado, respeita-se a potencialidade e personalidade individuais, visto que há uma variedade de inteligências existentes nesse espaço". Se utilizado a partir das questões de africanidade ou de jogos africanos pode potencializar as questões étnico-raciais culturais e ambientais.

Por fim, a literatura afro-brasileira (70\%), os desenhos (70\%) e os filmes brasileiros (50\%) também tiveram representatividade significativa, o que evidencia diversidade de possibilidades para abordagem das relações étnico-raciais na escola bilíngue.

\section{Conclusão}

Este estudo objetivou identificar a percepção de educadores de uma escola bilíngue sobre a educação para as relações étnico-raciais e verificar que temas/metodologias consideram fundamentais para trabalhar com Libras e relações étnico-raciais na escola. Pode-se inferir que apesar de conhecerem a legislação e saberem que existe a obrigatoriedade de trabalhar a História e a Cultura Afro-brasileira nos estabelecimentos públicos e privados, a maioria não possuía formação inicial ou continuada para desenvolver a temática em sala de aula.

Ficou evidente o quanto a formação continuada de professores é crucial quando abarca metodologias que vem ao encontro das necessidades dos professores, tais como: as brincadeiras e jogos educativos. Os docentes também enfatizam a importância da literatura afro-brasileira, os desenhos e os filmes brasileiros como metodologias significativas para o ensino da cultura afro-brasileira e Libras.

Como perspectiva futura, pretende-se utilizar o questionário analisado como diagnóstico para realização de uma formação de professores com os sujeitos da pesquisa, no âmbito do Mestrado Profissional em Educação da Universidade Federal do Pampa - Campus Jaguarão, tendo como temática a Libras e as relações étnico-raciais.

Salientamos que o mérito da pesquisa em educação é indiscutível, uma vez que essa tem evoluído na conquista da democratização do ensino. Entretanto, o desenvolvimento das pesquisas científicas que envolvam a Libras e as relações étnicoraciais simultaneamente é, ainda, um processo nascente e em construção, muito se tem a caminhar.

Por fim, destacamos a inclusão da Libras como disciplina curricular obrigatória na educação básica, a formação docente, a inclusão social e laboral, o combate ao preconceito e a discriminação étnico-racial. Compreendemos que a ausência de conhecimento e aprofundamento teórico dos docentes sobre a educação para relações étnico-raciais pode acentuar o racismo 
e preconceito nos espaços escolares, mesmo estando indicado em diferentes legislações e políticas públicas educacionais esse tema não é plenamente abordado nos contextos escolares.

\section{Referências}

Alves, S. S., Stoll, V. G., \& Lima, Q. C. E. (2016). (Re) Educação das relações étnico-raciais: ação-reflexão na formação de professores na Educação Básica. Revista de Linguagens, Artes e Estudos em Culturas, 2(1), 13-29.

Alves, S. S., Vieira, S. S., Stoll, V. G., \& Lima, Q. C. E. (2021). Educação para as Relações Étnico-Raciais: concepções e práticas dos/as docentes da Educação Infantil. Research, Society and Development, 10(3), e12810313141.

Brasil (2002). Lei n. 10.436, de 24 abril de 2002. Casa Civil.

Cerqueira, D., \& Coelho, D. S. C. (2017). Democracia racial e homicídios de jovens negros na cidade partida (No. 2267). Texto para Discussão.

Costa, M. F. V. (2004). Jogo simbólico, discurso e escola: uma leitura dialógica do mundo. In: Cruz, S., \& Petralanda, M. Linguagem e educação da criança. Fortaleza: UFC.

França, M. G. B., \& Barroso, M. C. da S. (2021). O uso de libras com alunos surdos nas disciplinas de Matemática e Ciências. Research, Society and Development, 10(6), e22610614886.

Gil, A. C. (2019) Métodos e técnicas de pesquisa social. (7a ed.). Atlas.

Gil, A. C. (2017). Como elaborar projetos de pesquisa (6a ed.). Atlas.

Marques, C. J. F., Araújo, L. A. da S., Loureiro, M. C. B., \& Munguba, M. C. (2020). A Educação Bilíngue na Universidade Federal do Ceará: o perfil do alunado do curso de Letras Libras. Research, Society and Development, 9(7), e233973891

Minayo, M. C. D. S. (2017). Pesquisa social: teoria, método e criatividade. Vozes.

Miranda, M. G. (2012). Produção didática pedagógica: Lei 10639/2003 e a resistência na escola. Curitiba: Secretaria de Estado da Educação Paraná.

Muller, B. C. (2013). Uma experiência pedagógica com jogos africanus na formação continuada de professores de matemática no município de Serra do Espírito Santo. Revista Eletrônica Debates em Educação Científica e Tecnológica, 3(1), 41-51.

Munanga, K. (2005) Superando o racismo na escola. Brasília: MEC/SECAD.

Oliveira, E. N., França, S.., Silva, E. N., Rodrigues, C. S., Ziesemer, R. P. M., Feijó, I. G. S., Ximenes Neto, F. R. G., Vasconcelos, M. I. O., Aragão, J. M. N., Costa, M. S. A., Lima, G. F., \& Furtado, J. S. (2021). Discriminação racial de jovens negros no Brasil: revisão integrativa. Research, Society and Development, 10(14), e214101422013.

Pimenta, S. G. (2013). Educação em Direitos humanos e formação de professores. In: Relações raciais e formação de professores(as). São Paulo: Cortez, 119137.

Rodrigues, T. C., \& Silva, A. F. (2021). Didáticas das relações étnico raciais: contribuições propositivas para a formação inicial de professores. Roteiro, (46), e26442.

Saviani, D. (2010). Interlocuções pedagógicas. Editora Autores Associados.

Skliar, C. (1998). A escola para surdos e as suas metas: repensando o currículo numa perspectiva bilíngue e multicultural. Cadernos Educacionais FaE/UFPel, (12), 21-34.

Unesco. (1994). Declaração de Salamanca. Unesco.

Vale, J. da S., Costa, L. G. da, \& Vale, D. R. de S. (2021). Currículo surdo: a luta contra a hegemonia ouvinte inclusiva. Research, Society and Development, $10(11)$, e424101119794. 